\title{
Maturation of Eupneic Respiration in the Neonatal Monkey
}

\author{
WILLIAM A. LAFRAMBOISE, RICHARD E. TUCK, DAVID E. WOODRUM, AND \\ ROBERT D. GUTHRIE \\ Department of Pediatrics, Division of Neonatal and Respiratory Diseases, University of Washington, \\ Seattle, Washington 98195
}

\section{Summary}

Comparison between 21 2-day-old infant monkeys and 1721 day-old infants during non-rapid eye movement sleep demonstrated that minute ventilation $\left(\dot{V}_{l}\right)$ increased from $141 \pm 30$ to $257 \pm 65 \mathrm{ml} / \mathrm{min}$ secondary to elevations in tidal volume $\left(V_{T}\right)$ and mean inspiratory flow $\left(V_{T} / T_{i}\right)$ with little change in respiratory timing. These volumetric parameters of ventilation as well as functional residual capacity remained significantly augmented when standardized for gain in body weight. Dynamic lung compliance increased from $0.69 \pm 0.19$ to $0.89 \pm 0.39 \mathrm{ml} / \mathrm{cm} \mathrm{H}_{2} \mathrm{O}$ with age while inspiratory pulmonary resistance did not change. Effective elastance fell significantly with maturation $(5.27 \pm 1.51$ $\mathrm{cm} \mathrm{H}_{2} \mathrm{O} / \mathrm{ml}$ on day 2 versus $4.15 \pm 1.35 \mathrm{~cm} \mathrm{H}_{2} \mathrm{O} / \mathrm{ml}$ on day 21) while effective impedance was elevated postnatally. The postnatal ventilatory gain $\left(80 \%\right.$ increase in $\left.\dot{V}_{I}\right)$ was attributable to increases both in dynamic lung compliance $(30 \%)$ and inspiratory effort $(50 \%)$ as determined by esophageal pressure changes. Isometric occlusion pressures $\left(P_{0.1}, P_{0.2} \ldots P_{\max }\right)$ also significantly increased during this time span, suggesting that the increased ventilation resulted from an elevated respiratory drive.

\section{Abbreviations}

$V_{T}$, tidal volume

NREM, non-rapid eye movement sleep

$\dot{V}_{I}$, minute ventilation

$T_{i}$, inspiratory time

$T_{e}$, expiratory time

$T_{\text {tot }}$, total cycle duration

$P$, airway pressure

FRC, functional residual capacity

E'rs, effective elastance

I'rs, effective impedance

Although there is a large volume of information on respiration in the human newborn, child, and adult, the ventilatory changes during the first weeks of life have not been studied extensively in normal infants. What data are available indicate that the human newborn exbibits a marked increase in resting minute ventilation and tidal volume by the end of the first postnatal month when compared with values obtained during the 1st week of life $(8,15,27)$. In the few cases where growth parameters were considered, these ventilatory increases remained significant after standardization for the gain in weight, height, and surface area which occurred over this time span. The first month then is unusual since this augmentation of minute ventilation and tidal

Received August 2, 1983; accepted March 13, 1984.

Correspondence may be addressed to William A. LaFramboise, Department of Pediatrics, RD-20, Division of Neonatal and Respiratory Diseases, University of Washington, Seattle, WA 98195.

This work was supported in part by National Institutes of Health Grant HL19187 and Regional Primate Center Grant RR00166. volume relative to size in early infancy contrasts with the decreasing trend established in children (4 years and older) which continues into adulthood $(12,18)$.

We have observed an analogous maturational increase in resting ventilation in the infant monkey, Macaca nemestrina, while studying the responses of this species to various respiratory stimuli. In this paper, we present an analysis of ventilatory data obtained on normal newborn monkeys during the 1st month of life. Since we measured pulmonary mechanics and performed end expiratory airway occlusions in our infants, we hoped to gain insight into potential mechanisms modulating the increase in basal ventilation in the monkey which might also be applicable to humans.

\section{MATERIALS AND METHODS}

Forty $M$. nemestrina infants were delivered by cesarean section at 155 days of gestation ( 0.92 of term) and were determined to be free of lung disease on the basis of arterial blood gases and clinical examinations. Chest roentgenograms were taken at birth if indicated by abnormal blood gas values or clinical symptoms. Two animals were eliminated from our "normal newborn" group on this basis such that 21 subjects were studied at 2 days of age and 17 between 21 and 26 days of age.

The two groups of infants studied were compared with a sample of nine infants delivered via spontaneous vaginal birth at the same gestational age and that did not undergo surgical intervention in the 21-26-day postnatal period with which we were concerned. The birth weights of the study groups were comparable to one another (day $2: 453 \pm 38 \mathrm{~g}$; day 21: $439 \pm 47$ $\mathrm{g})$ and to the spontaneously born infants $(444 \pm 39 \mathrm{~g})$ assuring us that we had chosen representative groupings of the normal primate population available. Our 3-week-old infants demonstrated a significant weight gain compared to the 2-day-old subjects $(75 \pm 34 \mathrm{~g})$ and commensurate with normal weight gain for $M$. nemestrina infants delivered spontaneously $(87 \pm 52 \mathrm{~g})$ so our subjects underwent normal growth for the 3-week duration of the study.

The infants were restrained in a supine position under a Servocontrolled radiant heat source on the day of a study. This system maintained abdominal surface to core temperature gradient at a minimum $\left( \pm 0.5^{\circ} \mathrm{C}\right.$ on day 2 and $\pm 1.0^{\circ} \mathrm{C}$ on day 21$)$ and resulted in a mean core temperature of $37.5 \pm 0.5^{\circ} \mathrm{C}$. An umbilical artery cannula, placed at birth, was available for withdrawing blood samples at 2 days of age while a femoral artery cutdown was performed for sampling at 21 days of age. A flexible tracheostomy tube (flow resistance $=0.25 \mathrm{~cm} \mathrm{H} \mathrm{H}_{2} \mathrm{O} /$ liter $/ \mathrm{min}$ at 3 liters $/ \mathrm{min}$ ) was surgically placed on day 2 after chloroprocaine $\mathrm{HCl}$ had been injected at the incision site for anesthesia. On day 21 , the tracheostomy tube placement (flow resistance $=0.10 \mathrm{~cm} \mathrm{H}_{2} \mathrm{O}$ / liter/min at 3 liters/min) and cutdown procedure required ketamine anesthesia $(5 \mathrm{mg} / \mathrm{kg})$. Data collection began $2 \mathrm{~h}$ after the 
preparatory surgery was completed and the anesthetic effects dissipated (16). Each animal was studied at one age only to eliminate any effect of repeated tracheal surgery on respiratory mechanics and because these subjects were also exposed to severe levels of hypoxia, hypercapnia, or resistive loading as part of other ongoing studies subsequent to the collection of these baseline ventilatory data.

Electroencephalogram, electrooculogram, electromyogram of posterior neck muscles, and heart rate were obtained from disc electrodes and simultaneously recorded on a polygraph (Beckman Accutrace) as described in a previous study (14).

The basic design of the system employed for data collection is shown in Figure 1. The subjects were connected to a low resistance (less than $0.1 \mathrm{~cm} \mathrm{H} \mathrm{H}_{2} \mathrm{O} / \mathrm{min} /$ liter at 3 liters/min on inspiration; $0.12 \mathrm{~cm} \mathrm{H}_{2} \mathrm{O}$ on expiration) nonrebreathing valve with a $0.35-\mathrm{ml}$ dead space. The tracheostomy surgery and use of the nonrebreathing valve had negligible effect on the sleeping infants as pretracheostomy ventilatory rates and blood gas values were not altered by these procedures. Respiratory flow was detected by a hot wire anemometer on the inspiratory port of the valve and the flow profile generated during a breath was integrated by a signal conditioner (Hewlett-Packard $8815 \mathrm{~A}$ ) to determine $V_{T}$ (13). The instrument was calibrated prior to each period of data collection. A pressure transducer (Gould P-50) monitored airway pressure through a sidearm of the tracheal tube.

Ventilation was measured during NREM sleep as the animal breathed humidified air at room temperature. An arterial blood sample $(0.5 \mathrm{ml})$ was drawn for analysis (Instrument Laboratories No. 713 blood gas analyzer) associated with a series of 10 end expiratory airway occlusions. The breath preceding an occlusion was designated the control breath provided it was consistent with the previous inspiratory cycles. $\dot{V}$, was calculated from the mean tidal volume and frequency of the control breaths. A minimum of five arterial blood gas samples and 50 airway occlusions during NREM sleep at each postnatal age comprised a successful study for each animal.

The timing components $T_{i}, T_{e}$, and $T_{t o t}$ were measured and from these values the "inspiratory duty cycle" $\left(T_{i} / T_{t o t}\right)$ and "mean inspiratory flow $\left(V_{T} / T_{i}\right)$ were calculated (23). The occluded breaths were analyzed for the airway pressure generated at 100-msec intervals $\left(P_{0.1}, P_{0.2}, P_{0.3}, P_{0.4}\right.$, and $\left.P_{0.5}\right)$ of the occluded inspiration as well as the maximum pressure $\left(P_{\max }\right)$ generated for that effort. The duration of the occluded inspiration $\left(T_{\text {i occ }}\right)$ was taken from onset of pressure development to the time at which $P_{\max }$ was reached.

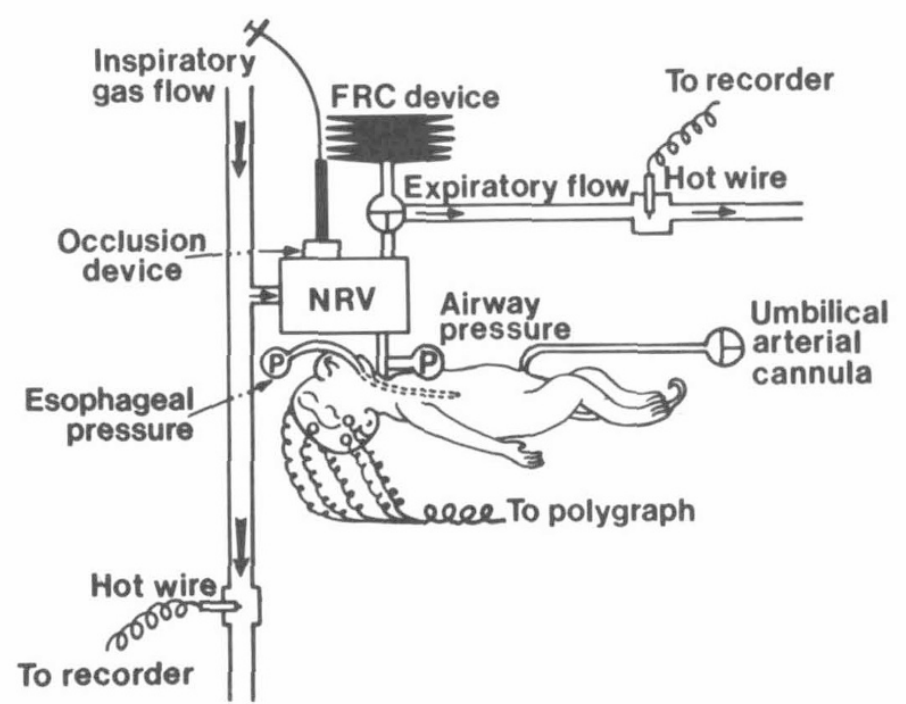

Fig. 1. The design of the system employed to carry out this study. $N R V$, nonrebreathing valve. On day 21 , the infants no longer had an umbilical arterial line and a femoral cannula was used for sampling arterial blood.
Measurements of pulmonary mechanics were made in 22 of the subjects studied. First, FRC was determined utilizing the nitrogen washout technique (11) with a minimum of three determinations made in each infant. Second, dynamic compliance was determined by placing a water-filled cannula of $15-\mathrm{cm}$ length and 1.4-mm internal diameter in the distal third of the esophagus to obtain changes in intrapleural pressure using a pressure transducer (Gould P-50) (22). This system would accurately reproduce (no phase lag or loss of amplitude) an oscillating pressure signal of up to $10 \mathrm{~cm} \mathrm{H}_{2} \mathrm{O}$ and $10 \mathrm{~Hz}$. Dynamic compliance was calculated from the pressure difference at points of zero flow from end expiration to end inspiration as the applied pressure needed to overcome the elastic recoil of the lungs in obtaining the tidal volume associated with that effort. These data were expressed as a volume change per unit of applied pressure and thus represent the dynamic compliance of the lungs (6). Third, resistance to airflow was determined in these infants by a modificaiton of the technique devised by Mead and Whittenberger (21) for total pulmonary resistance. The area of the esophageal pressure trace exceeding the elastic recoil line which intersects the zero flow points was considered to be the additional pressure required to overcome the resistance forces of the lungs. This area was computed by planimetry from the esophageal pressure trace. The upper airway resistive pressure contribution obtained by integrating the pressure profile generated at the tracheal tube opening was subtracted from the esophageal pressure area and the resulting resistive pressure increment was divided by the corresponding tidal volume. The result is the mean inspiratory pulmonary resistance.

The data obtained in this study were tested for changes of statistical significance using Student's $t$ test for unpaired variables. A $p$ value less than 0.05 was considered to represent a significant difference.

\section{RESULTS}

Minute ventilation increased markedly in the older subjects compared to the newborns during the 3-week interval secondary to an increase in tidal volume and mean inspiratory flow (Table 1). FRC increased significantly associated with the increase in ventilation while dynamic lung compliance and mean inspiratory pulmonary resistance did not statistically change (Table 2). Standardizing compliance and resistance for FRC resulted in a significant rise only in specific pulmonary resistance (Table 2). Arterial blood gases changed in association with the increase in ventilation as $\mathrm{PaO}_{2}$ rose and $\mathrm{PaCO}_{2}$ fell during the 3-week postnatal period (Table 3 ).

The volumetric indices of ventilation, $V_{T}$ and $V_{T} / T_{i}$, remained significantly elevated along with $\dot{V}_{I}$ after standardization for body weight. FRC also increased significantly after weight was taken into account (Fig. 2).

The mean pressures obtained during end expiratory airway occlusions and the volume changes for the control breaths preceding occlusion are plotted in 100-msec intervals in Figure 3. The pressures were higher on day 21 throughout the occlusion from $P_{0.1}$ to cessation of the occluded inspiratory effort. The volumes obtained on the control breaths did not differ between the two groups until $400 \mathrm{msec}$ into the breath and then remained elevated in the older infants until inspiration terminated. The esophageal pressure required for tidal inspiration increased with age but this trend did not achieve statistical significance either as a peak value or as a rate of pressure generation.

The ratio of peak occlusion pressure to tidal volume or $E^{\prime}$ rs was compared between age groups and found to fall significantly with age (Table 4). This value is reported to decrease with maturity at birth and increasing body size both within and across species $(1,26)$. When this value was standardized for weight change in our subjects, specific E'rs, the maturational fall no longer occurred while standardization for FRC reversed the direction of the change with age. Because timing differences in 
Table 1. Minute ventilation and components*

\begin{tabular}{cccccc}
\hline & $\begin{array}{c}\dot{V}_{I} \\
\left(\mathrm{ml} \cdot \mathrm{min}^{-1}\right)\end{array}$ & $V_{T}(\mathrm{ml})$ & $\begin{array}{c}V_{T} / T_{i} \\
\left(\mathrm{ml} \cdot \mathrm{sec}^{-1}\right)\end{array}$ & $\begin{array}{c}\text { Frequency } \\
\left(\text { breaths } \cdot \mathrm{min}^{-1}\right)\end{array}$ & $T_{i} / T_{\text {tot }}$ \\
\hline Day 2 & $141 \pm 30$ & $2.2 \pm 0.5$ & $4.6 \pm 0.9$ & $65 \pm 11$ & $0.51 \pm 0.05$ \\
$\bar{x} \pm \mathrm{SD}$ & 21 & 21 & 21 & 21 & 21 \\
$n$ & $257 \pm 65$ & $4.2 \pm 1.1$ & $8.2 \pm 2.2$ & $63 \pm 16$ & $0.53 \pm 0.07$ \\
Day 21 & 17 & 17 & 17 & 17 & 17 \\
$\bar{x} \pm$ SD & $p<0.001$ & $p<0.001$ & $p<0.001$ & NS & NS \\
$n$ & & & & & \\
\hline
\end{tabular}

$* \dot{V}_{l}, V_{T}, V_{T} / T_{i}$, respiratory frequency, and inspiratory duty cycle $\left(T_{i} / T_{t o t}\right)$. Statistical comparisons made across postnatal age. NS indicates no significant change.

Table 2. Pulmonary mechanics*

\begin{tabular}{|c|c|c|c|c|c|}
\hline & $\begin{array}{c}C_{L} \\
\left(\mathrm{ml} \cdot \mathrm{cm}^{-1} \mathrm{H}_{2} \mathrm{O}\right)\end{array}$ & $C_{L} / \mathrm{FRC}$ & $\begin{array}{c}R_{L} \\
\left(\mathrm{~cm} \mathrm{H} \mathrm{H}_{2} \mathrm{O} \cdot \mathrm{ml} \cdot \mathrm{sec}^{-1}\right)\end{array}$ & $R_{L} \cdot \mathrm{FRC}$ & FRC \\
\hline $\begin{array}{l}\text { Day } 2 \\
\quad \bar{x} \pm \mathrm{SD}\end{array}$ & $0.69 \pm 0.19$ & $0.12 \pm 0.07$ & $0.13 \pm 0.05$ & $0.79 \pm 0.25$ & $6.1 \pm 1.8$ \\
\hline $\begin{array}{c}\text { Day } 21 \\
\bar{x} \pm \mathrm{SD}\end{array}$ & $0.89 \pm 0.39$ & $0.10 \pm 0.06$ & $0.12 \pm 0.04$ & $1.28 \pm 0.60$ & $10.4 \pm 2.6$ \\
\hline$n$ & $\begin{array}{l}11 \\
\text { NS }\end{array}$ & $\begin{array}{c}8 \\
\text { NS }\end{array}$ & $\begin{array}{c}8 \\
\text { NS }\end{array}$ & $\begin{array}{c}8 \\
p<0.001\end{array}$ & $\begin{array}{c}8 \\
p<0.001\end{array}$ \\
\hline
\end{tabular}

${ }^{*}$ Dynamic lung compliance $\left(C_{L}\right)$, mean inspiratory pulmonary resistance $\left(R_{L}\right)$, and FRC for the subjects in which pulmonary mechanics were studied. Specific dynamic compliance $\left(C_{L} / \mathrm{FRC}\right)$ and specific pulmonary resistance $\left(R_{L} \cdot \mathrm{FRC}\right)$ values are also presented with statistical comparisons for age group differences. NS indicates no significant difference.

Table 3. Arterial blood gas values*

\begin{tabular}{cccc}
\hline & $\mathrm{PaO}_{2}$ (torr) & $\mathrm{PaCO}_{2}$ (torr) & $\mathrm{pH}$ \\
\hline Day 2 & $72.2 \pm 8.0$ & $38.8 \pm 3.6$ & $7.37 \pm 0.04$ \\
$\bar{x} \pm \mathrm{SD}$ & & & \\
$n$ & 21 & 21 & 21 \\
Day 21 & & & \\
$\bar{x} \pm \mathrm{SD}$ & $87.4 \pm 5.4$ & $33.3 \pm 1.9$ & $7.38 \pm 0.03$ \\
$n$ & 17 & 17 & 17 \\
& $p<0.001$ & $p<0.001$ & $\mathrm{NS}$ \\
\hline
\end{tabular}

* Arterial oxygen, carbon dioxide, and $\mathrm{pH}$ values for the two age groups tested.

$T_{i}$ and $T_{i o c c}$ can effect $\mathrm{E}^{\prime} \mathrm{rs}$, the occluded pressure and volume obtained $200 \mathrm{msec}$ into their respective inspiratory efforts were converted to a ratio $\left(P_{0.2} / V_{0.2}\right)$ and compared. This value for I'rs changed in a manner opposite that of $E^{\prime}$ rs being insignificantly elevated with maturation. Normalizing this value for weight had no statistical effect on the ratio while using FRC for this purpose caused I'rs to fall significantly.

The major volumetric and pressure changes in this study are summarized in Figure 4 as a percentage change from day 2 to day 21 . Clearly, a major change in $\dot{V}_{I}$ occurred even after standardization for weight increase in our subjects and this change occurred secondary to an increase in tidal volume and mean inspiratory flow. FRC also increased markedly over the time span tested and remained so after standardization for weight. All indices of inspiratory effort obtained during isometric occlusion maneuvers increased over the duration of this study.

\section{DISCUSSION}

The ventilatory adjustments made by the newborn monkey during the first 3 weeks of life share interesting parallels with the manner in which the human infant adapts to the extrauterine environment. Minute ventilation increased markedly during the first 3 weeks of life in the monkey secondary to an augmentation of tidal volume and mean inspiratory flow, characteristic changes demonstrated to occur in the human over the same time span
(7, 15, 27). The alterations in $\dot{V}_{l}, V_{T}$, and $V_{T} / T_{i}$ in the monkey do not simply reflect growth rate since they remain significant after standardization for weight gain. The few serial measurements in humans of these ventilatory parameters normalized for weight show the same trend $(7,27)$. Finally, the changes in specific dynamic lung compliance, specific pulmonary resistance, and FRC which were present in the monkey have also been recorded in the human neonate after the major increases in compliance and FRC associated with the immediate postdelivery period have occurred $(6,30)$. The overwhelming similarity in the development of a stable resting ventilation in the neonatal pigtail monkey compared to the human infant indicates that this subhuman primate species may serve as a model for studies of postnatal adjustment of eupneic ventilation applicable to the human infant.

Attempts to utilize the end expiratory occlusion maneuver in the healthy human newborn have been few and the results variable because of the technical difficulties in obtaining pressure tight access to respiratory airflow without adding a large dead space or otherwise disturbing the sleeping infant. The monkey model eliminates these difficulties by utilizing the tracheostomy tube to overcome these problems. It was determined that iso-
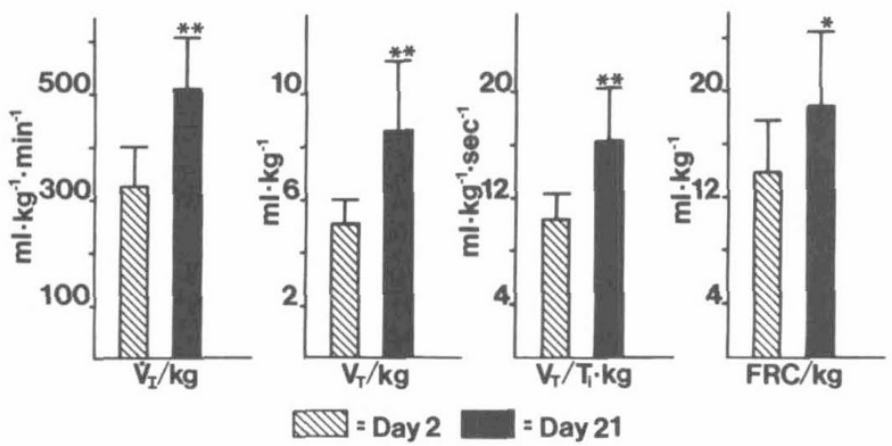

Fig. 2. Volumetric indices of ventilation and FRC after standardization for weight. $\bar{x} \pm \mathrm{SD}$ for 21 subjects on day 2 and 17 on day 21 .**, $^{* *}$ $<0.001 ;{ }^{*}, p<0.05$. 
metric occlusion pressures are uniformly higher in the older infants both as raw values and as a rate of pressure generation. To our knowledge, this is the first documentation of such a developmental trend in human or subhuman primates. The similarity of the ventilatory and mechanical changes during the first 3 weeks of life in the monkey and human infant lead us to hypothesize that occlusion pressures in human infants will increase over this same time span. Further support for a relationship between $P_{0.2}$ and ventilation corrected for growth is found

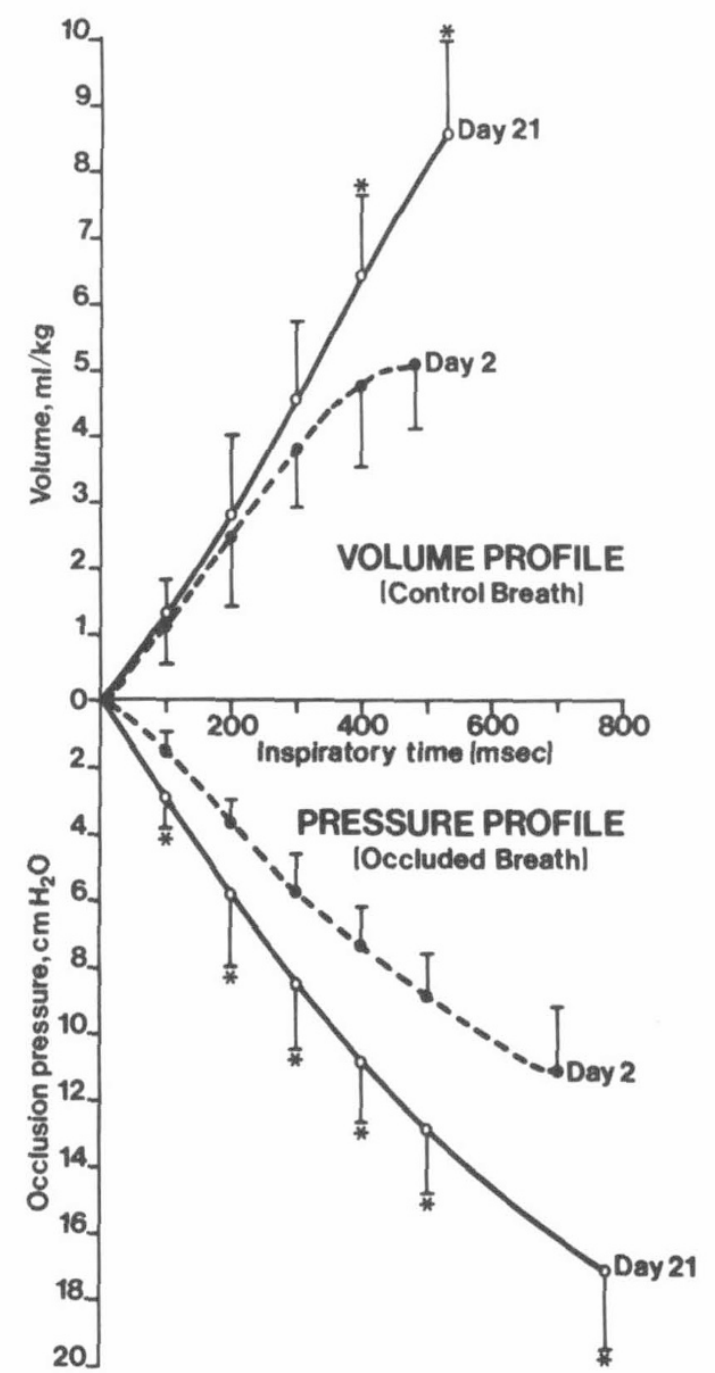

Fig. 3. Composite profile of volume and occluded pressure. $\bar{x} \pm \mathrm{SD}$ represented for $n=21$ on day $2, n=17$ on day 21 . Volume standardized for weight was elevated at $400 \mathrm{msec}$ of inspiration as well as end inspiration with age. Occlusion pressures were elevated throughout in the 3-week-old animals. ${ }^{*}, p<0.001$. in recent reports documenting concordant trends in these variables from childhood through adolescence $(12,18)$.

The age-related elevation of occlusion pressures during eupneic respiration in the neonatal monkey is evidence of an enhanced neuromuscular output of the respiratory system during postnatal maturation. Occlusion pressures have been interpreted further as an index of central neural respiratory drive with the caution that changes in the length-tension characteristics of the respiratory muscles can affect airway pressure development $(9,10,32)$. To this end, our measurement of FRC represents an attempt to control for such changes. The increase in occlusion pressures in these infants occurred despite an FRC increase which would reduce airway occlusion pressure in adult subjects with a constant phrenic nerve activity (9).

The potential for developmental changes in the phrenic nerve, chest wall structure, and the respiratory muscles precludes us from interpreting the gain in occlusion pressure as necessarily representing a heightened central respiratory output. 1) Postnatal change in phrenic nerve fiber diameter and myelination may alter discharge pattern and, hence, the activation sequence of diaphragmatic muscle motor end plates (24). This could increase tension generation and occlusion pressure with maturation due to adjustments in nerve electrical properties rather than increased bulbopontine activity. 2) Alterations in chest wall tone and configuration might distribute inspiratory muscle force more effectively with less effort dissipated on the highly compliant chest wall typical of the newborn (2). 3) FRC changes with age do not necessarily reflect changes in muscle length-tension states but could actually indicate a change in sarcomere length altering the overall contractile dynamics of the respiratory muscles. 4) The diaphragm undergoes maturational changes in fiber type

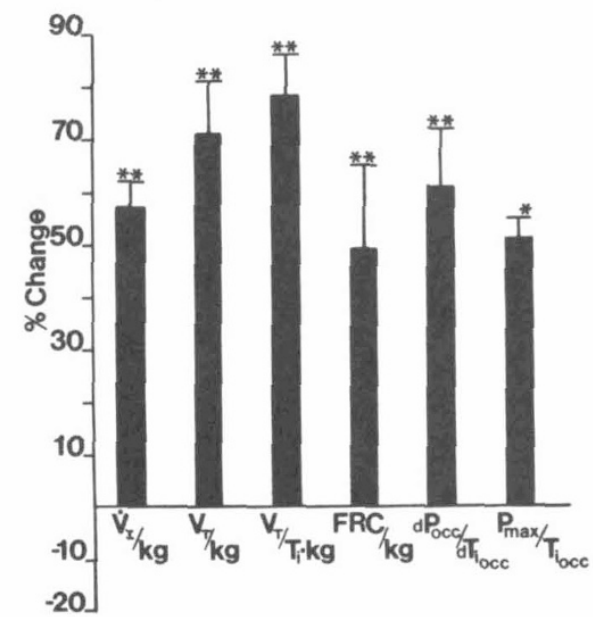

Fig. 4. Major volumetric and pressure adjustments with maturation. All values standardized for weight where appropriate and expressed as a percentage increase on day 21 above day 2 value. Bars represent $\tilde{x} \pm$ SD. ${ }^{* *}, p<0.001 ;{ }^{*}, p<0.05$.

Table 4. Effective elastance and impedance*

\begin{tabular}{|c|c|c|c|c|c|c|}
\hline & $\begin{array}{c}\mathrm{E}^{\prime} \mathrm{rs} \\
\left(\mathrm{cm} \mathrm{H} \mathrm{H}_{2} \mathrm{O} / \mathrm{ml}\right)\end{array}$ & $\begin{array}{c}\mathrm{E}^{\prime} \mathrm{rs} \cdot \mathrm{wt} \\
\left(\mathrm{cm} \mathrm{H} \mathrm{H}_{2} \mathrm{O} \cdot \mathrm{kg} / \mathrm{ml}\right)\end{array}$ & $\begin{array}{l}\mathrm{E}^{\prime} \mathrm{rs} \cdot \mathrm{FRC} \\
\left(\mathrm{cm} \mathrm{H} \mathrm{H}_{2} \mathrm{O}\right)\end{array}$ & $\begin{array}{c}\mathrm{I}^{\prime} \mathrm{rs} \\
\left(\mathrm{cm} \mathrm{H} \mathrm{H}_{2} \mathrm{O} / \mathrm{ml}\right)\end{array}$ & $\begin{array}{c}\mathrm{I}^{\prime} \mathrm{rs} \cdot \mathrm{wt} \\
\left(\mathrm{cm} \mathrm{H} \mathrm{H}_{2} \mathrm{O} \cdot \mathrm{kg} / \mathrm{ml}\right)\end{array}$ & $\begin{array}{l}\mathrm{I}^{\prime} \mathrm{rs} \cdot \mathrm{FRC} \\
\left(\mathrm{cm} \mathrm{H} \mathrm{H}_{2} \mathrm{O}\right)\end{array}$ \\
\hline \multicolumn{7}{|l|}{ Day 2} \\
\hline $\begin{array}{l}\bar{x} \pm \mathrm{SD} \\
n\end{array}$ & $\begin{array}{c}5.27 \pm 1.51 \\
21\end{array}$ & $\begin{array}{c}2.29 \pm 0.68 \\
21\end{array}$ & $\begin{array}{c}25.7 \pm 8.8 \\
13\end{array}$ & $\begin{array}{c}3.57 \pm 0.95 \\
21\end{array}$ & $\begin{array}{c}1.49 \pm 0.74 \\
21\end{array}$ & $\begin{array}{c}22.7 \pm 5.7 \\
13\end{array}$ \\
\hline \multicolumn{7}{|l|}{ Day 21} \\
\hline $\begin{array}{l}\bar{x} \pm \mathrm{SD} \\
n\end{array}$ & $\begin{array}{c}4.15 \pm 1.35 \\
17 \\
p<0.05\end{array}$ & $\begin{array}{c}2.13 \pm 0.75 \\
17 \\
\text { NS }\end{array}$ & $\begin{array}{c}43.3 \pm 10.1 \\
8 \\
p<0.001\end{array}$ & $\begin{array}{c}4.35 \pm 1.92 \\
17 \\
\text { NS }\end{array}$ & $\begin{array}{c}2.11 \pm 1.32 \\
17 \\
\text { NS }\end{array}$ & $\begin{array}{c}11.02 \pm 6.8 \\
8 \\
p<0.001\end{array}$ \\
\hline
\end{tabular}

*Effective elastance $\left(P_{\max } / V_{T}\right)$ and effective impedance $\left(P_{0.2} / V_{0.2}\right)$ derived from occlusion pressure and inspired volume data. Specific elastances and impedances based on weight were available for all infants while specific E'rs and I'rs using FRC were calculated in only those infants from whom we obtained FRC. 
and distribution which may increase their rate of tension development and airway pressure generation upon isometric contraction (25). 5) Recruitment of intercostal and accessory muscles via segmental reflexes during occlusion may be subject to postnatal increases in sensitivity and force output. In light of these considerations, the elevated occlusion pressures represent only superficial evidence supporting the hypothesis that central neural output during eupneic respiration increases during the first 3 weeks of life in the infant monkey. In order to prove this hypothesis, an investigation will be necessary to determine whether the occlusion maneuver provides an accurate index of phrenic and bulbopontine output during the newborn period in the presence of so many other developmental changes.

The elevation in $\dot{V}_{I}$ with maturation occurred in association with a small increase in dynamic lung compliance (30\%) which did not attain statistical significance. This finding is consistent with previous work which has shown that compliance undergoes major adjustments within the first 4 to $24 \mathrm{~h}$ of life and then is similar to adult measures when standardized for lung volume using FRC (4). The increase in specific pulmonary resistance that occurred with age is also consistent with reports for the human neonate $(3,30)$. These data suggest that an augmentation of inspiratory effort is necessary to account for the $80 \%$ maturational rise in $\dot{V}_{l}$, particularly since timing components of ventilation changed little while $\dot{V}_{T}$ nearly doubled. In support of this, esopahgeal pressures were approximately $50 \%$ higher in the older infants. Thus, the increase in $\dot{V}_{I}$ can be accounted for by the sum of the changes in $C_{L}$ and $P_{e}$. We recognize that total respiratory compliance changes are important over this time span but doubt that changes in chest wall compliance would significantly improve distensibility of the respiratory system. In fact, data collected in other newborn models provide evidence to the contrary, i.e. that the chest wall becomes more rigid over this time span indicating that the inspiratory effort applied to the total respiratory system may be even higher with age (2). These data, along with the elevated occlusion pressures support the finding that an augmented inspiratory effort, in conjunction with an improvement of the mechanical status of the respiratory system, mediates the increase in ventilation during the first 21 days of neonatal life.

Effective elastance has been used as an index of respiratory system stability and has been demonstrated to fall with postnatal maturation in human infants while effective impedance is lower in the newborn than the adult $(1,33)$. The neonatal monkey undergoes similar changes in these indices but the determinants of such adjustments are not clear. Passive respiratory system compliance, vagal modulation of airway tone and stretch receptor activity, and the intrinsic properties of the respiratory muscles contribute to E'rs in anesthetized animals (20). Compliance and flow resistance should play the same role in $E^{\prime}$ rs and I'rs so the different directions these variables take postnatally may reflect a stronger vagal influence on inspiratory timing in the immature infant. There have been numerous attempts to validate this hypothesis in the unanesthetized human infant but the results have been inconsistent $(19,26,31)$. The data collected by the infant monkey then, provide corroborative evidence for the importance of maturation on effective inspiratory mechanics but serial follow-up of individual subjects will be necessary to confirm the role of vagal modulation on these measures.

Beyond the evidence we have presented to explain the method by which ventilation is augmented with age, i.e. increased inspiratory effort, the question remains to explain why ventilation increases. One logical possibility is that ventilation rises to meet the elevated oxygen demands of the rapidly growing neonate (5). The human infant undergoes proportionate increases in both oxygen consumption and minute ventilation during the first months of life supporting this theory $(17,27,29)$. Recent work has reported a progressive decline in $P_{0.1}, V_{T} / T_{i}$, and $\dot{V}_{I}$ relative to weight in children over a time span in which basal metabolic rate has been shown to decline $(12,28)$. Although the direction of these changes in older children is opposite to what we suggest occurs in infants, the fact that they occur concurrently lends support to our hypothesis that the changes our infants displayed in occlusion pressure, mean inspiratory flow, tidal volume, and ventilation are linked to oxygen consumption.

Since the blood gas changes we measured did not strictly reflect the adjustment of ventilation with age in our subjects, it is likely that a decrease in shunt and/or reduction in physiological dead space also contributed to changes in blood gas tensions along with increased metabolic rate.

In summary, the neonatal monkey in NREM sleep demonstrates the previously reported increase in $\dot{V}_{l}, V_{T}$, and FRC typical of human postnatal development and thus provides an excellent model to study human postnatal ventilatory maturation. The ventilatory increase in our subjects was attributable to some improvement in pulmonary mechanics but was also associated with an increase in inspiratory effort which may reflect an increase in neuromuscular output. Future studies are warranted to determine whether or not 1) the increase in effort is of central origin and modulated by increased phrenic nerve activity, 2) whether phrenic transmission is constant postnatally and neuromuscular coupling improved, or 3) whether the fiber content and/or configuration of the diaphragm provides greater force output with maturation for a given neural input. Further, the link of postnatal ventilatory demand with metabolic rate remains to be clarified during this time span.

Acknowledgments. The authors express their thanks to Dr. Jacob Hildebrandt for formulating the method whereby we were able to calculate inspiratory pulmonary resistance in our subjects. We also appreciate the skilled assistance of Cheryl McAuliffe and Rachel Novotony in collecting the data and Nancy Meyers for her help in reducing the data. We thank Gail Terzi for her skill in drawing all illustrations and charts. Finally we thank Jo Ann Jarrett for her patient and careful secretarial assistance.

\section{REFERENCES}

1. Adler SM, Thach BT, Frantz ID 1976 Maturational changes of effective elastance in the first 10 days of life. J Appl Physiol 40:539

2. Avery ME, Cook CD 1961 Volume-pressure relationships of lungs and thorax in fetal, newborn, and adult goats. J Appl Physiol 16:1034

3. Briscoe WA, DuBois AB 1958 The relationship between airway resistance, airway conductance, and lung volume in subjects of different age and body size. J Clin Invest 37:1279

4. Chu JS, Dawson P, Klaus M, Sweet AY 1964 Lung compliance and lung volume measured concurrently in normal full-term and premature infants. Pediatrics 34:525

5. Cook CD, Cherry RB, O’Brien D, Karlberg P, Smith CA 1955 Studies of respiratory physiology in the newborn infant. 1. Observations on normal premature and full-term infants. J Clin Invest 34:975

6. Cook CD, Sutherland JM, Segal S, Cherry RB, Mead J, McIlroy MB, Smith CA 1957 Studies of respiratory physiology in the newborn infant. III Measurement of mechanics of respiration. J Clin Invest 36:440

7. Cross KW 1949 The respirtory rate and ventilation in the newborn baby. J Physiol (Lond) 109:459

8. Deming J, Hanner JP 1936 Respiration in infancy. 1. A study of rate, volume, and character of respiration in healthy infants during the neonatal period. Am J Dis Child 51:823

9. Eldridge FL 1975 Relationship between respiratory nerve and muscle activity and muscle force output. J Appl Physiol 39:567

10. Eldridge FL, Vaughn KZ 1977 Relationship of thoracic volume and airway occlusion pressure: muscular effects. J Appl. Physiol 43:312

11. Fowler WS 1950 Specific tests of pulmonary function. Methods Med Res 2:181

12. Gaultier C, Perret L, Bowie M, Baury A, Girard F 1981 Occlusion pressure and breathing pattern in healthy children. Respir Physiol 46:71

13. Godal A, Belenky DA, Standaert TA, Woodrum DE, Grimsrud L, Hodson WA 1976 Application of the hot-wire anemometer to respiratory measurements in small animals. J Appl Physiol 40:275

14. Guthrie RD, Standaert TA, Hodson WA, Woodrum DE 1980 Sleep and maturation of eucapnic ventilation and $\mathrm{CO}_{2}$ sensitivity in the premature primate. J Appl Physiol 48:347

15. Haddad GG, Epstein RA, Epstein MAF, Leistner HL, Marino PA, Mellins RB 1979 Maturation of ventilation and ventilatory pattern in normal sleeping infants. J Appl Physiol 46:998

16. Hargrove JC, Heavner JE, Guthrie RD, Morton WR 1980 Age dependent ketamine pharmacodyamics in the pigtail monkey (Mocaca nemestrina). Proc West Pharmacol Soc 23:129 
17. Hey EN 1969 The relation between environmental temperature and oxygen consumption in the newborn baby. J Physiol (Lond) 200:589

18. Jammes Y, Auran Y, Gouvernet J, Delpierre S, Grimand C 1979 The ventilatory pattern of conscious man according to age and morphology. Bull Eur Physiopathol Respir 15:527

19. Kirkpatrick SML, Olinsky A, Bryan MH, Bryan AC 1976 Effect of premature delivery on the maturation of the Hering-Breuer inspiratory inhibitory reflex in huam infants. J Pediatr 88:1010

20. Lynne-Davies P, Couture J, Pengelly LD, West D, Bromage PR, Milic-Emili J 1971 Partitioning of immediate ventilatory stability to added elastic loads in cats. J Appl Physiol 30:814

21. Mead J, Whittenberger JL 1953 Physical properties of human lungs measured during spontaneous respiration. J Appl Physiol 5:779

22. Mead J, Mcllroy MB, Selverstone NJ, Kriete BC 1955 Measurement of intraesophageal pressure. J Appl Physiol 7:491

23. Milic-Emili J, Grunstein MM 1976 Drive and timing components of ventilation. Chest 70:131 (July suppl)

24. Nystrom B 1968 Fibre diameter increase in nerves to "slow-red" and "fastwhite" cat muscles during postnatal development. Acta Neurol Scand 44:265
25. Nystrom B 1968 Histochemistry of developing cat muscles. Acta Neurol Scand 44:405

26. Olinsky A, Bryan MH, Bryan AC 1974 Influence of lung inflation on respiratory control in neonates. J App. Physiol 36:426

27. Rigatto H, Brady J, Dela Torre Verduzco R 1975 Chemoreceptor reflexes in preterm infants. I. The effect of gestational and postnatal age on the ventilatory response to inhalation of $100 \%$ and $15 \%$ oxygen. Pediatrics 55:604

28. Robertson JD, Reid, DO 1952 Standards for the basal metabolism of norma people in Britain. Lancet 1:940

29. Scopes JW, Ahmed I 1966 Minimal rates of oxygen consumption in sick and premature newborn infants. Arch Dis Child 41:407

30. Stocks J 1977 The functional growth and development of the lung during the first year of life. Early Human Dev 3:285

31. Thach BT, Frantz ID, Adler SM, Taeusch HW 1978 Maturation of reflexes influencing inspiratory duration in human infants. J Appl Physiol 45:203

32. Whitelaw WA, Derenne J-P, Milic-Emili J 1975 Occlusion pressure as a measure of respiratory center output in conscious man. Respir Physiol 23:181

33. Zin WA, Rossi A, Milic-Emili 1983 Model analysis of respiratory responses to inspiratory resistive loads. J Appl Physiol 55:1565

\title{
Comparative Effects of Verapamil, Nifedipine, and Diltiazem on Contractile Function in the Isolated Immature and Adult Rabbit Heart
}

\author{
ROBERT J. BOUCEK, JR., MARC SHELTON, MICHAEL ARTMAN, PHILLIP S. MUSHLIN, \\ VAUGHN A. STARNES, AND RICHARD D. OLSON
}

Departments of Pediatrics, Biochemistry, and Pharmacology, Vanderbilt Universty School of Medicine, Nashville, Tennessee 37232

\section{Summary}

The effects of postnatal development on the systolic and diastolic responses to pharmacologic blockade of the slow inward calcium current were investigated in blood-perfused hearts isolated from immature (14-21-day-old) and adult rabbits. Isovolumic left ventricular developed pressure, resting pressure, and maximal rate of pressure development $(+d P / d t)$ at cumulative doses of either verapamil, nifedipine, or diltiazem were determined by means of an intracavitary balloon. Myocardial contractile function in the immature heart was more sensitive to pharmacologic blockade of the slow inward calcium current than is the adult heart. Doses of verapamil, or nifedipine, that comparably reduced pretreatment developed pressure and $+d P / d t$ were approximately $\mathbf{1 0}$-fold less in immature as compared to the adult heart. The dose of diltiazem which reduced developed pressure and $d P / d t$ by $50 \%$ was 3 -fold less in immature as compared to the adult heart. Verapamil and nifedipine decreased resting pressure in the adult but not in the immature heart. Conversely, diltiazem decreased resting pressure in the immature while not affecting resting pressure in adult hearts. Thus, postnatal cardiac development affects both the systolic and diastolic responses to

Received January 6, 1983; accepted February 8, 1984.

Address reprint requests and correspondence to Robert J. Boucek, Jr. Department of Pediatrics D-2217, Vanderbilt Medical Center, Nashville, TN 37232.

This work was supported in part by a Grant-in-Aid from the American Heart Association-Tennessee Affiliate, Biomedical Research Support Grant RR-5424, and the March of Dimes Birth Defects Foundation. R.D.O. is a Research Investigator of the American Heart Association, Tennessee Affiliate and recipient of National Institutes of Health Grant HL 28711. calcium channel blockade. In addition, diltiazem appears to be qualitatively and quantitatively different from verapamil and nifedipine with respect to the age-related cardiac effects of calcium channel blockade.

\section{Abbreviations}

SR, sarcoplasmic reticulum

SL, sarcolemma

LV, left ventricular

In the mammalian heart, excitation is coupled to contraction by intracellular $\mathrm{Ca}$ cycling mediated by the concerted functions of the SR and SL (5). Several lines of evidence suggest that the relationship between SL and SR in the regulation of excitationcontraction coupling may undergo significant changes during postnatal development.

Ultrastructural evidence suggests significant postnatal development of the SR and T-tubule network (13, 16, 24, 25). Ca"triggered" Ca release by SR can first be demonstrated in skinned cardiac fibers $48 \mathrm{~h}$ after birth $(3,4)$. There is also suggestive evidence that the $\mathrm{Ca}$ reuptake properties of SR, important in relaxation, also develops after birth $(16,22,28)$. Postnatal differences in cardiac contractile responses to extracellular $\mathrm{Ca}(23,26)$, lanthanum (7), manganese (7), and caffeine (13), tension development under voltage-clamp conditions (16) suggest that: (a) a new source of "activator" Ca develops with the postnatal development of the SR and T-tubule system; and (b) trans-sarcolem- 